\title{
CONSTITUCIONALIDADE E CONVENCIONALIDADE DA LEI DE ANISTIA BRASILEIRA
}

\author{
Walter Claudius Rothenburg \\ CONSTITUTIONALITY AND CONVENTIONALITY \\ OF THE BRAZILIAN AMNESTY LAW
}

\section{RESUMO}

A LEI DE ANISTIA BRASILEIRA (LEI N. 6.683/1979) FOI OBJETO DE CONTROLE DE CONSTITUCIONALIDADE PELO SUPREMO TRIBUNAL FEDERAL E DE CONTROLE DE CONVENCIONALIDADE PELA CORTE InTERAMERICANA dE Direitos Humanos. Enquanto o STF CONSIDEROU A LEI COMPATÍVEL COM A CONSTITUICÃ̃ DE 1988 , A CIDH CONSIDEROU-A INCOMPATIVEL COM A CONVENÇão AMERICANa de Direitos Humanos, POR ENTENDER QUE AS GRAVES VIOLAÇÕES A DIREITOS HUMANOS PRATICADAS POR AGENTES DA DITADURA NÄO PRESCREVEM E DEVEM SER INVESTIGADAS E PUNIDAS. IMPORTA DEFINIR O ÂMBITO DA JURISDIÇÃO INTERNA E DA INTERNACIONAL, E A POSSIBILIDADE DE CONCILIACÃO. DOUTRINA E JURISPRUDÊNCIA FORAM UTILIZADAS EM UMA ABORDAGEM ANALITICO-DEDUTIVA, EM QUE SE VERIFICOU QUE O STF AINDA PODE RECONHECER E DAR CUMPRIMENTO À DECISÃO INTERNACIONAL. A AFIRMACÃO DO DIREITO FUNDAMENTAL À MEMÓRIA, À VERDADE E À REPARAÇÃO, QUE CARACTERIZAM A JUSTIÇA DE TRANSIC̣ÃO, IMPÕE A INVALIDADE DA LEI DE ANISTIA.

\section{PALAVRAS-CHAVE}

ANISTIA; CONTROLE DE CONSTITUCIONALIDADE; CONTROLE DE CONVENCIONALIDADE; CRIMES CONTRA A HUMANIDADE; JUSTIÇA DE TRANSIC̣ÃO

\begin{abstract}
THE BRAZILIAN AMNESTY LAW (N. 6.683/1979) WAS THE SUBJECT OF JUDICIAL REVIEW BY THE SUPREME COURT AND CONTROL OF CONVENTIONALITY BY THE AMERICAN COURT OF Human RIgHTS. WHILE THE SUPREME COURT RULED tHE LAW COMPATIBLE WITH THE CONSTITUTION OF 1988, THE ACHR CONSIDERED IT INCOMPATIBLE WITH THE AMERICAN CONVENTION ON HUMAN RIGHTS, FOR SERIOUS HUMAN RIGHTS VIOLATIONS COMMITTED BY AGENTS OF THE DICTATORSHIP DO NOT PRESCRIBE AND SHOULD BE INVESTIGATED AND PUNISHED. IT IS IMPORTANT TO DEFINE THE SCOPE OF THE DOMESTIC AND INTERNATIONAL JURISDICTION, AND THE POSSIBILITY OF CONVERGENCE BETWEEN THE DECISIONS. DOCTRINE AND JURISPRUDENCE WERE USED IN AN ANALYTIC-DEDUCTIVE APPROACH, WHICH FOUND THAT THE SUPREME COURT CAN STILL RECOGNIZE AND COMPLY WITH THE INTERNATIONAL DECISION. THE ASSERTION OF THE FUNDAMENTAL RIGHT TO MEMORY, TO TRUTH AND REPARATION, WHICH CHARACTERIZE TRANSITIONAL JUSTICE, REQUIRES THE INVALIDITY OF THE AMNESTY LAW.
\end{abstract}

\section{KEYWORDS}

AMNESTY; CONSTITUTIONALITY CONTROL; CONVENTIONALITY CONTROL; CRIMES AGAINST HUMANITY; TRANSITIONAL JUSTICE

A luta do homem contra o poder é a luta da memória contra o esquecimento.

MILAN KUNDERA 


\section{i Direito Constitucional e Direito Internacional:}

ESTRANHAMENTO EM RELAÇÃo À LEI DE ANISTIA BRASILEIRA

Os encontros e desencontros entre o Direito Constitucional e o Direito Internacional (perceba-se que a própria sequência em que agora foram apresentados os dois ramos jurídicos denuncia alguma tendência subconsciente ou velada deste constitucionalista) projetam-se no confronto entre o controle de constitucionalidade e o controle de convencionalidade de que é objeto a Lei de Anistia brasileira (Lei n. 6.683/1979).

Em 29 de abril de 2010, o Supremo Tribunal Federal rejeitou, por maioria expressiva de votos, a inconstitucionalidade da Lei 6.683/1979, ao julgar improcedente a Arguição de Descumprimento de Preceito Fundamental 153/DF. Porém, logo em seguida, em 24 de novembro de 2010, a Corte Interamericana de Direitos Humanos, no caso Gomes Lund e outros vs. Brasil, julgou, por unanimidade, a Lei de Anistia brasileira contrária à Convenção Americana de Direitos Humanos (Pacto de San José da Costa Rica, 1969).

A respeito desse caso internacional, lembram Sabadell e Dimoulis (2011, p. 85) que,

[e]m 1995, as ONGs Centro pela Justiça e o Direito Internacional (CEJIL) e o Human Rights Watch/Americas deram início a um procedimento ante a Comissão Interamericana de Direitos Humanos visando a abertura de um processo frente a Corte Interamericana, em nome dos desaparecidos da guerrilha do Araguaia e seus familiares.

Completa Carvalho Ramos (2011) que

[s]omente em 2009, a Comissão processou o Brasil perante a Corte Interamericana de Direitos Humanos, sustentando que o Brasil violou a Convenção Americana de Direitos Humanos (tratado ratificado em 1992 pelo Estado), devendo responder pela detenção arbitrária, tortura e desaparecimento forçado de 70 pessoas, entre membros do Partido Comunista do Brasil (PC do B) e camponeses da região como resultado de operações do Exército empreendidas entre 1972 e 1975 com o objetivo de erradicar a Guerrilha do Araguaia, no contexto da ditadura militar brasileira $(1964-1985)$.

Com as decisões divergentes do Supremo Tribunal e da Corte Interamericana, instaurou-se uma desinteligência acerca da validade daquela lei.

Todavia, o autor da ADPF 153/DF, Conselho Federal da Ordem dos Advogados do Brasil, opôs embargos de declaração em razão de supostas contradições e omissões da decisão interna. Tais embargos oferecem ao Supremo Tribunal Federal excelente 
oportunidade para pronunciar-se acerca do confronto entre sua decisão de inconstitucionalidade e a decisão de inconvencionalidade (incompatibilidade com as normas internacionais de tratados) proferida pela Corte Interamericana de Direitos Humanos.

O objetivo dessa reflexão não é a crítica à decisão do Supremo Tribunal Federal, que aceitou a conformidade da Lei n. 6.683/1979 à Constituição brasileira ${ }^{1}$ (decisão que deve ser tomada por definitiva); mas sim a possibilidade e oportunidade de alinhamento do Supremo Tribunal Federal à decisão posterior da Corte Interamericana de Direitos Humanos, por diverso fundamento.

Os juízos de constitucionalidade e convencionalidade inauguram circuitos relativamente diversos e independentes, sendo possível que o Supremo Tribunal Federal afirme a compatibilidade da Lei n. 6.683/1979 com a Constituição brasileira de 1988 e que a Corte Interamericana de Direitos Humanos afirme a incompatibilidade da Lei de Anistia com a Convenção Americana de Direitos Humanos. Como esclarecem Favoreu e outros (2001, p. 164), "não há correlação absoluta entre os dois níveis, ainda que seja recomendável que ela exista tendo em conta uma preocupação de coerência e harmonização das duas ordens jurídicas, interna e internacional”.

A Constituição brasileira não veda (e tal vedação não teria validade no âmbito internacional) que se realize o controle de convencionalidade por corte internacional, ainda que o mesmo ato tenha sido objeto de controle de constitucionalidade em âmbito interno. Ao contrário, é possível afirmar que nossa Constituição admite e até estimula essa abertura, em dispositivos que:

- Estabelecem como princípios das relações internacionais a "prevalência dos direitos humanos" (art. 4 , II) e a "solução pacífica dos conflitos" (art. 4, VII);

- Não excluem outros "direitos e garantias" fundamentais decorrentes dos tratados internacionais $\left(\operatorname{art} .5^{\circ}, \S 2^{\circ}\right.$ ) e atribuem a estes a possibilidade de serem aprovados com equivalência às emendas constitucionais $\left(\operatorname{art.~} 5^{\circ}, \S 3^{\circ}\right.$ );

- Acatam a "jurisdição de Tribunal Penal Internacional" (art. 5 $§ 4^{\circ}$ ) e pugnam "pela formação de um tribunal internacional dos direitos humanos" (art. $7^{\circ}$ do Ato das Disposições Constitucionais Transitórias);

- Autorizam o deslocamento de competência para a investigação e julgamento de graves violações de direitos humanos, "com a finalidade de assegurar o cumprimento de obrigações decorrentes de tratados internacionais de direitos humanos" (art. 109, § $5^{\circ}$ ).

A Constituição brasileira também não afirma sua própria superioridade incontrastável, que seria incompatível com o reconhecimento que faz ao Direito Internacional. ${ }^{2}$ 


\section{Direito Constitucional e Direito Internacional de MÃos} DADAS E ATADAS: CONSTITUCIONALIDADE X CONVENCIONALIDADE

O controle de constitucionalidade e o controle de convencionalidade têm algo em comum e algo de distinto. Trata-se de um mesmo fenômeno de aferição de conformidade a um parâmetro, o que, no universo do Direito, significa aferir a validade de um ato em vista dos padrões de juridicidade. O controle de constitucionalidade verifica se um ato é compatível com a Constituição, enquanto o controle de convencionalidade verifica se um ato é compatível com a convenção (tratado) internacional.

Apesar de ambas as modalidades de controle serem versões de um mesmo fenômeno e fruto da mesma lógica (ROTHENBURG, 2010, p. 30), podem chegar a resultados diversos. Um ato pode ser considerado válido do ponto de vista constitucional, ou seja, ser aprovado pelo controle de constitucionalidade, mas inválido do ponto de vista convencional, ou seja, ser reprovado pelo controle de convencionalidade. Ou vice-versa: apesar de considerado compatível com o parâmetro convencional, o ato pode ser tido como incompatível com o parâmetro constitucional. "Uma lei contrária a um tratado não é por isso contrária à Constituição”, já teve oportunidade de afirmar o Conselho Constitucional francês (FAVOREU et al., 2001, p. 167).

É o que se passa com a Lei n. 6.683/1979, cuja incompatibilidade com a Constituição brasileira de 1988 foi rejeitada pelo Supremo Tribunal Federal, mas foi reconhecida como incompatível com a Convenção Americana de Direitos Humanos pela Corte Interamericana de Direitos Humanos.

Contudo, ambos os fundamentos, de Direito interno e de Direito Internacional, são requeridos para a validade de um ato, ou seja, o ato deve ser conforme a Constituição de determinado Estado e conforme o(s) tratado(s) internacional(is) para ser considerado válido. A incompatibilidade com algum desses parâmetros é suficiente para que o ato seja destituído de validade. Essa é a tendência do mundo contemporâneo, em que o Direito Internacional afirma-se por ser cada vez mais conhecido e cada vez mais praticado, e torna-se uma exigência tão grave quanto o Direito Constitucional. Não se tolera que um ato subsista à avaliação de sua incompatibilidade com as normas internacionais (convencionalidade). Entretanto, também não se abdica da necessidade de conformidade do ato com a Constituição, no âmbito mais específico de cada Estado. O ato deve sustentar-se tanto em termos de constitucionalidade quanto de convencionalidade.

A análise em âmbito interno da compatibilidade de um ato com a Constituição normalmente não suscita reflexões acerca da convencionalidade. O que pode acontecer e ocorre com cada vez mais frequência é a invocação, quando do controle de constitucionalidade, de situações semelhantes no Direito Internacional (e no Direito de outros Estados), bem como da jurisprudência das cortes internacionais (e das cortes estrangeiras). Uma influência recíproca, certamente impulsionada pela facilidade de comunicação no mundo contemporâneo. 
O Supremo Tribunal Federal não realiza controle "abstrato" de convencionalidade. ${ }^{3}$ Apenas quando as normas internacionais são incorporadas ao sistema constitucional e passam a integrar o bloco de constitucionalidade (como se dá, por exemplo, com os tratados internacionais de direitos humanos aprovados internamente com o procedimento das emendas constitucionais, nos termos do art. $5^{\circ}, \S 3^{\circ}$, da Constituição) é que servem de parâmetro - mas, ainda assim, ao controle de constitucionalidade.

Embora as peculiaridades de cada ordenamento jurídico interno sustentem um controle de constitucionalidade que prescinde, as mais das vezes, de uma reflexão acerca da compatibilidade do ato questionado com as normas internacionais, ocorre uma comunicação cada vez mais frequente e intensa entre os vários ordenamentos jurídicos internos, e destes com o Direito Internacional. A validade jurídica então já não se basta com a Constituição. Foi-se o tempo em que pouco importavam as normas de Direito Internacional nas análises jurídicas internas, em que se considerava suficiente (ou simplesmente exclusivo) o controle de constitucionalidade, ou seja, em que a Constituição era tida como "começo jurídico absoluto" (SABADELL; DIMOULIS, 2011, p. 84).

A interlocução do Direito Constitucional interno e estrangeiro, e destes com o Direito internacional, traduz um "diálogo de fontes" que, em termos de Direito Constitucional, é referido como "interconstitucionalismo" (CANOTILHO, 2006, p. 266), "transconstitucionalismo" (NEVES, 2009, p. 242 e s.) ou "cross-constitucionalismo" (TAVARES, 2009), e é apontado como uma das características do constitucionalismo contemporâneo (neoconstitucionalismo): a "tendência 'expansiva"” do constitucionalismo, um "constitucionalismo transnacional” (ARAGON REYES, 2007, p. 38-39), “constitucionalismo supranacional” (PAGLIARINI, 2009, p. 126, com enfoque na experiência da União Europeia) ou - como tenho preferido dizer - um "constitucionalismo internacional". Forma-se uma plataforma partilhada, com o "estabelecimento de uma espécie de 'gramática' jurídico-constitucional comum”, a partir da “aproximação cada vez maior entre as diversas ordens constitucionais nacionais”, como anota, com propriedade, Sarlet (2009, p. 167 e 168).

Aproveitam-se os documentos legislativos (leis) e as experiências judiciais (jurisprudência) alheias; aproximam-se inclusive os modelos institucionais (por exemplo, a existência de Cortes Constitucionais e suas homólogas Cortes Internacionais). A jurisprudência constitucional e a convencional influenciam-se reciprocamente; tendem a convergir em seus procedimentos, suas argumentações e suas decisões. Peter Häberle, na oportuna referência de Sarlet (2009, p. 169), fala da "tríade dinâmica constituída de textos normativos, doutrina (teorias) e jurisprudência”, a partir da qual será possível pensar na "formação de um direito constitucional comum".

A invocação dos textos normativos alienígenas e das decisões judiciais estrangeiras e internacionais sobre questões jurídicas semelhantes significa o emprego de fontes de Direito diversas daquelas do Direito interno. Em termos de sociologia jurídica - de 
acordo com Sabadell (2005, p. 106-108) -, trata-se do fenômeno da "transferência de direito" ou "transplante jurídico", que inclui o "empréstimo jurídico". 4

Uma consequência dessa interação, portanto, é a aproximação do resultado (e da própria fundamentação) dos controles de constitucionalidade e de convencionalidade. O conhecimento da realidade de outros ordenamentos, a verificação de problemas comuns e o fato de se tratar, tanto em âmbito interno quanto externo, de uma abordagem jurisdicional, mais a influência doutrinária recíproca, provocam decisões judiciais semelhantes.

A jurisdição constitucional brasileira vem utilizando com cada vez mais frequência o "argumento" do Direito estrangeiro e do Direito Internacional, o que revela a importância dessa invocação como estratégia para conferir densidade e capacidade de persuasão ao discurso jurídico. Designo isso como o uso retórico (ou argumentativo) do Direito estrangeiro e do Direito Internacional. Decisões relevantes e relativamente recentes do Supremo Tribunal Federal não apenas referem o Direito Internacional como alinham-se ao que é decidido pelas Cortes Internacionais.

Vejamos alguns evocativos exemplos da jurisprudência do Supremo Tribunal Federal em diversos campos do Direito. Advirto que não houve algum critério consistente na seleção das decisões. Busquei casos de repercussão em que lembrei existirem referências ao Direito estrangeiro ou ao Direito Internacional, ou aqueles em que, suspeitando havê-las, verifiquei-o.

a) Reconhecimento da imprescritibilidade do crime de racismo por meio de publicação antissemita (Habeas Corpus 82.424-2/RS, rel. Min. Maurício Corrêa, julgamento em 17/09/2003), com referência à "[a]desão do Brasil a tratados e acordos multilaterais".

b) Validade da penhora do bem de família do fiador no contrato de locação ${ }^{5}$ (RE 407.688-8/SP, rel. Min. Cezar Peluso, julgamento em 08/02/2006), com referência, no voto do Min. Celso de Mello, ao art. 25.1 da Declaração Universal de Direitos Humanos. 6

c) Necessidade de individualização da pena em face do regime integral de cumprimento em regime fechado (HC 82.959-7/SP, rel. Min. Marco Aurélio, julgamento em 23/02/2006), ${ }^{7}$ com referência, no voto do Min. Cezar Peluso, ao art. 5.6 do Pacto de São José da Costa Rica. ${ }^{8}$

d) Proibição da exigência de prisão para recorrer da condenação (HC 89.754-1/BA, rel. Min. Celso de Mello, julgamento em 13/02/2007), com referência ao art. 7.2 da Convenção Americana de Direitos Humanos. ${ }^{9}$ 
e) Validade da utilização de células-tronco embrionárias humanas produzidas por fertilização in vitro e não utilizadas, para fins de pesquisa e terapia (ADI 3.510/DF, rel. Min. Carlos Britto, julgamento em 28 e 29/05/2008), ${ }^{10}$ com referência, no voto do Min. Menezes Direito, ao art. 4.1 da Convenção Americana de Direitos Humanos; ${ }^{11}$ no voto da Min. Cármen Lúcia, aos art. 10 e 11 da Declaração Universal de Direitos Humanos e à Declaração Universal sobre o Genoma Humano e os Direitos Humanos (UNESCO, 1998); ${ }^{12}$ no voto do Min. Ricardo Lewandowski, ao art. 2.4 da Declaração Universal sobre Bioética e Direitos Humanos (UNESCO, 2005), ${ }^{13}$ dentre outros.

f) Invalidade da prisão civil do depositário infiel (Habeas Corpus 95.967-9/MS, rel. Min. Ellen Gracie, julgamento em 11/11/2008), com referência ao art. 11 do Pacto Internacional de Direitos Civis e Políticos (ONU, 1966) ${ }^{14}$ e ao art. 7.7 da Convenção Americana de Direitos Humanos, ${ }^{15}$ sendo especialmente relevante a decisão, tendo em vista que a Constituição brasileira prevê essa hipótese de prisão, ao lado da prisão civil do devedor de alimentos (art. $5^{\circ}$, LXVII).

g) Proibição de importação de pneus usados ou remoldados (ADPF 101 /DF, rel. Min. Cármen Lúcia, julgamento em 11/03/2009), com referência, pelo autor (Presidente da República), à Convenção da Basileia sobre o Controle de Movimentos Transfronteiriços de Resíduos Perigosos e seu Depósito (1989).

h) Validade da demarcação contínua da reserva indígena "Raposa-Serra do Sol" (Pet. 3.388/RO, rel. Min. Carlos Britto, julgamento em 19/03/2009), com referência, no voto da Min. Cármen Lúcia, à Declaração das Nações Unidas sobre os Direitos dos Povos Indígenas (ONU, 2007).

i) Invalidade de restrições à imprensa ${ }^{16}$ (ADPF 130/DF, rel. Min Carlos Britto, julgamento em 30/04/2009), com referência, no voto do Min. Celso de Mello, à jurisprudência do Tribunal Constitucional espanhol e da Corte Europeia de Direitos Humanos.

j) Invalidade da exigência de formação superior (universitária) para o exercício da profissão de jornalista (RE 511.961/SP, rel. Min. Gilmar Mendes, julgamento em 17/06/2009), com referência ao art. 13 da Convenção Americana de Direitos Humanos ${ }^{17}$ e à jurisprudência da Corte Interamericana de Direitos Humanos.

k) Validade da união civil de pessoas do mesmo sexo (ADI 4.277/DF e ADPF 132/RJ, rel. Min. Ayres Britto, julgamento em 04-05/05/2011), com diversas referências ao Direito estrangeiro, inclusive da União Europeia, nos votos, por exemplo, do 
relator, do Min. Gilmar Mendes e do Min. Celso de Mello, que cita os Princípios de Yogyakarta (Indonésia, 2006). ${ }^{18}$

Ainda que por tratar-se de um fenômeno relativamente recente e incipiente possa faltar rigor metodológico na utilização do Direito estrangeiro e do Direito Internacional pela jurisprudência (FIGUEIREDO, 2009, p. 68), ${ }^{19}$ o fato é que o Supremo Tribunal Federal tem-se alinhado à tendência contemporânea de estabelecer um diálogo proveitoso com fontes normativas estrangeiras. Pode-se verificar, mais ainda, o respeito com que o Direito Internacional é acolhido, a ponto de se lhe conferir precedência para (re)orientar a jurisprudência nacional. Os casos da invalidade da prisão civil do depositário infiel e da invalidade da exigência de formação universitária para a prática do jornalismo demonstram a importância conferida pelo Supremo Tribunal Federal ao Direito Internacional. A propósito do primeiro caso, anota Figueiredo (2009, p. 65) que se

revelou uma importante disposição do Supremo Tribunal Federal a estabelecer um diálogo constitucional com a Corte Interamericana de Direitos Humanos, compreendendo que a proteção internacional dos direitos humanos deve ser acolhida por qualquer Tribunal evitando conflitos entre as diversas ordens jurídicas envolvidas.

O Direito Constitucional de diversos Estados assemelha-se e tende a caminhar de mãos dadas com o Direito Internacional, cuja generalidade e comunidade conferemlhe certa primazia. Esse diálogo preferencial é facilitado por cláusulas de recepção contidas em Constituições contemporâneas, que Carvalho Ramos (2004) considera “cláusulas abertas' de compatibilização com os mandamentos internacionais”.

As Constituições de Portugal (1976) e da Espanha (1978) fornecem ilustração do reconhecimento expresso e da preferência dada ao Direito Internacional. Preceitua a Constituição portuguesa, sobre o "âmbito e sentido dos direitos fundamentais": "Os preceitos constitucionais e legais relativos aos direitos fundamentais devem ser interpretados e integrados de harmonia com a Declaração Universal dos Direitos do Homem.” (art. 16.2). Já a Constituição espanhola dispõe que "las normas relativas a los derechos fundamentales y a las libertades que la Constitución reconoce se interpretarán de conformidad con la Declaración Universal de Derechos Humanos y los tratados y acuerdos internacionales sobre las mismas materias ratificados por España" (art. 10.2). Para Canotilho e Moreira (2007, p. 367), trata-se do "princípio da interpretação em conformidade com a Declaração Universal”.

O itinerário da influência do Direito Internacional sobre o Direito interno pode ser resumido sob a seguinte perspectiva otimista: de um modelo de desconhecimento ou de menosprezo, para um modelo retórico ou de reforço, então para um modelo 
de aplicação e, finalmente, para um modelo de prevalência. Empolga-se Pagliarini (2009, p. 132-133), referindo-se a Kelsen, com a perspectiva de "um mundo em que o Direito das Relações Internacionais seria o elemento de validade de todas as outras ordens normativas".

Não se trata, contudo - e é sempre importante ressaltar -, da impossibilidade de contrastar o Direito Internacional. O critério decisivo, também aqui, não é o da superioridade formal e apriorística de algum dos âmbitos do Direito, seja o interno, seja o internacional. Nem pruridos nacionalistas de uma defesa intransigente da soberania estatal, nem laivos universalistas de uma intrínseca bondade da comunidade das nações. Quanto ao Direito Internacional, Sabadell e Dimoulis (2011, p. 95) duvidam enfaticamente de sua virtude: "Quem compartilha essa crença não traz provas e muito menos explica a bondade do direito internacional".

Importa verificar qual ordenamento melhor atende os direitos fundamentais. Especificamente no caso dos atos cruéis de repressão política cometidos por agentes investidos do poder de Estado no contexto de várias ditaduras latino-americanas, a aplicação dada à Convenção Americana de Direitos Humanos oferece um tratamento jurídico mais adequado que o apresentado com base na relutante legislação brasileira.

Tendo como foco o chamado direito à memória, à verdade e à reparação, podemos apontar as possibilidades do Direito Internacional, que:

a) é capaz de apontar parâmetros avançados para orientar e constranger os Estados (função indicativa do Direito Internacional);

b) é capaz de oferecer uma alternativa jurídica externa para a insuficiência do Direito interno (função substitutiva do Direito Internacional);

c) é capaz de apresentar um quadro normativo próprio e distinto, talvez nem concorrente, do Direito interno (função autônoma do Direito Internacional).

Como anotam Weichert e Fávero (2009, p. 519),

[s]empre que o direito interno de um país (ou suas instituições) não for apto a punir os autores desses delitos [como os crimes contra a humanidade], deverá ser aplicado o direito internacional para garantir a responsabilidade pessoal do perpetrador da violação.

O reconhecimento da prioridade das decisões de Cortes internacionais, quando favoráveis aos direitos fundamentais, compete às mais diversas autoridades nacionais. Os órgãos judiciários internos devem aplicar diretamente tais decisões internacionais e não dependem, para tanto, da edição de lei pelo Parlamento, conforme já decidiu 
a Corte Europeia de Direitos Humanos. ${ }^{20}$ Não se deve confundir, assim, a validade interna do texto normativo (tratado, convenção...) de Direito Internacional, que está condicionado à internalização (normalmente por meio de lei do Poder Legislativo), com a validade interna das decisões internacionais, que pressupõem a validade dos textos normativos de Direito Internacional em que se baseiam, mas que não dependem de interposição legislativa e devem ser aplicadas diretamente, inclusive pelas autoridades judiciárias internas.

Mesmo com a intenção explícita de destacar essa tendencial harmonia entre o Direito Constitucional e o Internacional, não olvidemos da possibilidade de divergências, como ocorre com a avaliação da Lei de Anistia brasileira. Divergências que hão de ser superadas. No caso, as "mãos dadas" com que devem andar o Direito Constitucional (pela voz do Supremo Tribunal Federal) e o Direito Internacional (pela expressão da Corte Interamericana de Direitos Humanos) apresentam-se com "mãos atadas". Com efeito, se o Supremo Tribunal Federal optasse pela alternativa radical de negar cumprimento à decisão da Corte Interamericana, deveria "declarar inconstitucional o reconhecimento brasileiro da jurisdição obrigatória da Corte Interamericana, forçando a denúncia da Convenção Americana de Direitos Humanos pelo Brasil”, como aponta Carvalho Ramos (2011). Contudo, não deve ser essa a disposição do Brasil e de suas autoridades. Ademais, o inusitado rechaço à Convenção Americana não surtiria efeitos práticos específicos, haja vista que, ainda nas palavras de Carvalho Ramos,

[m]esmo a denúncia da Convenção Americana pelo Brasil (que entendemos ser impossível, dada a natureza materialmente constitucional desse tratado) não atingiria as sentenças já prolatadas contra o Brasil, que devem ser cumpridas, pois o artigo 68.1 da Convenção Americana de Direitos Humanos determina que 'os Estados-partes na Convenção comprometemse a cumprir a decisão da Corte em todo caso em que forem partes' (combinado com o artigo 78.2).

Tudo está a sugerir um alinhamento do Supremo Tribunal Federal ao entendimento da Corte Interamericana de Direitos Humanos, sem necessidade de infirmar o julgamento de improcedência da ADPF 153/DF. Basta reconhecer que de outro juízo se trata: a Corte Interamericana não desautorizou o Supremo tribunal Federal quando fez uma avaliação distinta da incompatibilidade da Lei n. 6.683/1979 com base na Convenção Americana de Direitos Humanos.

\section{A decisão do Supremo Tribunal Federal na ADPF 153}

A questão da dupla - e concorrente - avaliação da validade da Lei n. 6.683/1979 (Lei de Anistia) será apreciada a partir de uma abordagem estritamente jurídica, ${ }^{21}$ 
que não ignora a influência de outras perspectivas, como a política e a moral, mas que considera os parâmetros normativos de avaliação e as consequências normativamente previstas dos controles de validade (constitucionalidade e convencionalidade).

\section{I ANTERIORIDAde DAS NORMAS INCRiminadoraS}

Princípios jurídicos basilares para a aferição jurídica da Lei n. 6.683/1979 são o da legalidade (previsão normativa) e o da irretroatividade das leis incriminadoras, consagrados positivamente na Constituição brasileira de 1988, ${ }^{22}$ na Declaração Universal de Direitos Humanos da Organização das Nações Unidas (1948) ${ }^{23}$ e na Convenção Americana de Direitos Humanos (1969), ${ }^{24}$ e admitidos com certo consenso pelos juristas, embora a aplicação e efetividade de tais princípios tenham sido desprezadas em diversos momentos da história.

No caso da Lei n. 6.683/1979, havia parâmetros internacionais de Direito positivo em vigor no Brasil que infirmavam sua validade. ${ }^{25}$ Cite-se a Resolução n. 95, editada quando da primeira sessão da Assembleia Geral da ONU em 11 de dezembro de 1946, que confirmou "os princípios de Direito Internacional reconhecidos pelo Estatuto do Tribunal de Nuremberg e as sentenças de referido Tribunal", sendo que esse estatuto formalizou os crimes contra a humanidade, "constituam ou não uma violação da legislação interna do país onde foram perpetrados”. ${ }^{26}$ Citem-se também os "Princípios de Direito Internacional reconhecidos no Estatuto do Tribunal de Nuremberg e no julgamento do Tribunal”, editados em 1950 (com base na Resolução n. 177 (II), de 21 de novembro de 1947), dentre os quais o Princípio II: "O fato de o Direito interno não impor uma punição a um ato que constitui um crime segundo o Direito Internacional não exime a pessoa que cometeu o ato da responsabilidade perante o Direito Internacional”. Citem-se ainda as Resoluções n. 2.184 e n. 2.202, de 1966, que condenaram como crimes contra a humanidade “(i) a política de Portugal de violação dos direitos econômicos e sociais da população indígena de territórios estrangeiros sob seu domínio e (ii) a prática do apartheid pelo governo da África do Sul"; tais resoluções identificam a ocorrência de crime contra a humanidade "independentemente da existência de guerra ou de atentado à paz” (WEICHERT; FÁVERO, 2009, p. 518-520).

Ademais, já estávamos em 1964, duas décadas após a conflagração da Segunda Grande Guerra, e tanto a doutrina quanto a prática jurídicas reconheciam, do ponto de vista material, que "[n]unca uma norma jurídica permitiu a tortura, da mesma forma que ela continua não sendo permitida hoje” (SWENSSON JR., 2010, p. 34); do ponto de vista processual, era reconhecido o princípio da inafastabilidade da persecução das graves violações dos direitos fundamentais, a despeito de eventual resistência por parte de algum Estado. Não é razoável pretender que os agentes públicos que participaram do cometimento de graves violações a direitos fundamentais em repressão política não tivessem percepção do caráter criminoso de suas condutas. 
Não devemos ignorar que o princípio da legalidade somente encontra sentido no Estado Democrático de Direito. Em regimes ou situações de arbítrio e menosprezo pelos direitos fundamentais, tal princípio não apenas perde seu sentido como serve ao oposto.

O Brasil é um dos fundadores da Organização das Nações Unidas e, portanto, deve adotar suas deliberações. No âmbito internacional, formam-se costumes com força cogente (jus cogens), uma espécie de norma jurídica que não está sujeita à "incorporação formal (via ratificação) ao direito interno brasileiro para poder ser aplicad[a] em conjunto com o direito interno" (WEICHERT; FÁVERO, 2009, p. 538). Embora o costume internacional possa ser considerado insuficiente para atender as rigorosas exigências de legalidade do Direito Criminal, ${ }^{27}$ ele reforça e é reforçado pela existência de textos normativos internacionais como os anteriormente referidos. O Supremo Tribunal Federal reconhece a força cogente do costume internacional, inclusive com prevalência sobre o Direito interno, de que é ilustração a admissão da imunidade de jurisdição aos Estados estrangeiros, como quanto ao descabimento de reclamação trabalhista em face de representação diplomática no país (WEICHERT, 2009, p. 156). ${ }^{28}$

A admissão de normas jurídicas que definem crimes contra a humanidade e determinam a punição é importantíssima em uma perspectiva temporal relativa não apenas ao passado, mas também ao futuro. Quanto ao passado, essa admissão permite a responsabilização dos autores de graves violações a direitos fundamentais segundo padrões jurídicos reconhecidos como vigentes já à época dos acontecimentos. Quanto ao futuro, reforça a aceitação de tais padrões jurídicos em termos cada vez mais firmes e expandidos, o que contribui para a consolidação e o aprimoramento da democracia (GUTMANN; THOMPSON, 2004, p. 174-175 - os autores tratam do "argumento histórico" e aludem a "parâmetros morais").

Passa a ser menos importante a qualificação dos atos de repressão praticados por agentes públicos como "crimes políticos" ou "conexos com estes", conforme dispõe a Lei n. 6.683/1979. Advirta-se, entretanto, para a polêmica a respeito. A doutrina de Direito Criminal costuma apontar, para a qualificação de um crime como político, a pretensão de desestabilização do Estado (do poder constituído); ora, no caso da repressão, o que se tem é justamente o contrário, vale dizer, a pretensão de manter e reforçar a estrutura de poder constituído, no sentido da preservação do regime (WEICHERT; FÁVERO, 2009, p. 550-554; WEICHERT, 2009, p. 140-142).

\subsection{IMPRESCRITIBILIDADE E INSUSCETIBILIDADE DE ANISTIA}

A Convenção sobre Imprescritibilidade dos Crimes de Guerra e dos Crimes contra a Humanidade, aprovada pela Assembleia da ONU em 1968, é um documento oficial previamente existente à boa parte do período coberto pela Lei de Anistia brasileira (2 de setembro de 1961 a 15 de agosto de 1979), e atende, portanto, à exigência da 
anterioridade. Ocorre que também a Convenção sobre Imprescritibilidade dos Crimes de Guerra e dos Crimes contra a Humanidade não é inovadora do ponto de vista jurídico, pois se apresenta como "a exteriorização formal de um conceito material que se consolidara através do costume internacional” (WEICHERT; FÁVERO, 2009, p. 532). Esse argumento supera a objeção da anterioridade parcial: já existia um consenso e uma prática jurídica internacionais no sentido da imprescritibilidade dos crimes contra a humanidade.

Havendo essa norma clara de Direito Internacional, também o argumento da falta de adesão expressa do Governo brasileiro não prospera. Com efeito, não seria razoável exigir que o regime de força da ditadura brasileira, representado pelo Governo oficial, reconhecesse expressamente todas as normas de Direito Internacional que poderiam comprometê-lo. A validade da manifestação de vontade de um Governo para a aceitação do Direito Internacional deve pressupor, também nesse aspecto, um regime democrático e representativo. A ausência de adesão por parte de um Governo ilegítimo não tem o condão de impedir a aplicação - quase necessariamente posterior à queda do regime espúrio - do Direito Internacional humanitário.

A revisão da interpretação a respeito da validade da Lei n. 6.683/1979 não é, assim, a pintura de um quadro anterior com cores atuais e distorsivas ou a manifestação irracional de um desejo psicótico de vingança. Os atos de repressão cometidos pelos agentes públicos caracterizavam crimes cuja punição ainda é devida e violações de direitos ainda reparáveis. Essa resposta jurídica nunca deixou de ser esperada e só não foi sempre ouvida porque as vozes eram abafadas. ${ }^{29}$

Mas não se deve desconsiderar a circunstância do momento no enfoque da justiça de transição, o que pode reclamar (re)configurações diversas. A interpretação jurídica da Lei de Anistia e do tratamento dado às violações de direitos fundamentais decorrentes da repressão política durante a ditadura militar não é imune ao tempo e depende, em muito, de um recuo temporal adequado. Nem o momento dos fatos, em que vigorava o regime de exceção, nem o momento imediatamente posterior, de transição muitas vezes complexa e frágil, oferecem condições e informações suficientes para interpretar o quadro jurídico com lucidez e liberdade. Carlos Nino (2006, p. 262) adverte que, na fase de transição, tentativas de perseguição dos responsáveis devem "equilibrar-se com a meta de preservar o sistema democrático". Tavares e Agra (2009, p. 70 e 73) aludem à “constância dos fatores reais de poder” e lembram que a própria transição democrática deu-se "sob a direção de forças identificadas com o regime anterior", razão por que "não houve condições fáticas para a punição dos que praticaram a tortura no período de exceção”.

Ao contrário da argumentação usualmente utilizada para justificar o instituto da prescrição, no sentido de que o passar do tempo apaga, no caso da justiça de transição o passar do tempo esclarece - e esclarece inclusive com a luz do Direito Internacional, que havia ficado ofuscado durante as trevas da ditadura. 
A reação jurídica penal não deve ser descartada nesse contexto. Conquanto haja dificuldades óbvias derivadas do tempo decorrido, que dificulta a produção de provas, encontra pessoas idosas ou falecidas e provoca uma comoção social menos intensa, a importância da efetividade do Direito continua a estar na punição dos responsáveis, na satisfação dada às vítimas e seus próximos, no evitar a reprodução de atos semelhantes no futuro, no fomentar a cultura de respeito aos direitos fundamentais.

A impunidade potencializa a continuidade de desrespeito a direitos fundamentais. Neil Kritz afirma que a anistia "pode impedir a distinção entre o passado e o futuro, trazendo a cultura da impunidade e a continuação da violência ao presente" (SAMPAIO; ALMEIDA, 2009, p. 254). Assim, deixar de investigar e punir as violações passadas caracteriza por si uma violação, porque contribui para novas violações, sempre incentivadas pela ausência de respostas adequadas. Como assevera Carlos Nino (2006, p. 263), "la omisión de un gobierno de investigar y perseguir violaciones de derechos humanos cometidas por un régimen anterior puede justamente ser categorizada como un abuso pasivo de derechos humanos si pone a esos bajo un riesgo futuro".

O Direito não deve resignar-se ao esquecimento, mas funcionar como importante instrumento da memória. O perdão e a renúncia à expectativa de ver punidos os agentes públicos violadores de direitos fundamentais não são um imperativo jurídico ou político, ${ }^{30}$ conquanto possam estar impregnados de valor moral ou religioso.

São muito evocativas a propósito as considerações de Ost (2005, p. 173), que aponta para a controvérsia existente a respeito da anistia ou "amnésia institucional". Citando Paul Ricoeur, Ost adverte para um preço muito alto a pagar, que envolve "todos os delitos do esquecimento", inclusive "o risco de banalizar o crime ou ainda neutralizar todos os valores, bons ou maus, colocando-os lado a lado numa medida comum de clemência, como quando se anistia os antigos opositores para melhor anistiar os antigos opressores”. Certos graus de violação de direitos fundamentais são indeléveis e não podem ser objeto de acordo político, de modo que nem pretensos representantes das vítimas dos crimes contra a humanidade praticados na repressão aos dissidentes nem as próprias vítimas poderiam renunciar validamente à punição jurídica (institucional) dos torturadores, estupradores, assassinos etc.

A expectativa dos oprimidos, perseguidos, torturados ou mortos, contudo, é muito importante. Afinal, em uma sociedade democrática, a anistia em relação a episódios da gravidade extrema dos crimes contra a humanidade não deve resumir-se a um ato oficial do Estado e não pode prescindir, em alguma medida, da aquiescência das vítimas, como acentuam Gutmann e Thompson (2004, p. 172-173). Os autores relatam a reação de uma mulher perante a Comissão da Verdade e Reconciliação da África do Sul após o regime de "apartheid", ao ouvir o testemunho do assassinato de seu marido e ser indagada se conseguiria perdoar: “'Nenhum governo pode perdoar.' Pausa. 'Nenhuma comissão pode perdoar.' Pausa. 'Somente eu posso perdoar.' Pausa. 'E eu não estou pronta para perdoar'”. 
O suposto acordo entre atores sociais que teria propiciado a Lei de Anistia brasileira não contou com uma ampla participação da população ou sequer de muitas das pessoas diretamente interessadas e implicadas (refiro-me a tantas vítimas da repressão e seus familiares, por exemplo). Tal acordo (duvidoso) não se sustenta, pois, em termos de democracia deliberativa. Algum acordo talvez até fosse possível com base na "economia da discordância moral" (GUTMANN; THOMPSON, 2007, p. 23), que levasse em consideração e reduzisse as divergências, e que, no caso da anistia, recusasse-a aos crimes mais atrozes perpetrados por agentes públicos (GUTMANN; THOMPSON , 2004, p. 183). Mas a Lei de Anistia brasileira foi "ampla, geral e irrestrita", com o provável propósito de albergar justamente as mais graves violações.

\subsection{Ilegitimidade dA LeI N. 6.683/1979}

Pressuposto de validade da Lei n. 6.683/1979 é a legitimidade de sua promulgação e interpretação. Trata-se de aspecto de contornos menos objetivos do que a questão da projeção temporal (retroatividade) da lei e mais influenciado por considerações político-ideológicas, porém nem por isso infenso a uma análise jurídica. Leis advindas de um regime de força, com reduzidíssima representação popular, podem ter sua validade questionada por causa da origem espúria. Embora tal questionamento coloque em risco a segurança jurídica, não é razoável desprezar a necessidade de esteio democrático para um ordenamento jurídico. Por razões práticas, não se consegue infirmar todas as numerosas leis produzidas no período da ditadura militar, que disciplinam os aspectos mais comuns do quotidiano e provavelmente não seriam muito diferentes se o contexto político outro fosse. Não assim, todavia, com relação às normas que tratam diretamente da sustentação do regime de força e, com ainda mais evidência, àquelas que pretendem blindá-lo de crítica futura. Essas padecem irremediavelmente da falta de legitimidade.

A Lei de Anistia brasileira foi produzida e imposta pelos detentores do poder político (e militar) na ocasião. Sofre, assim, de vício de (i)legitimidade, pois o Congresso Nacional que a aprovou não pôde manifestar livremente a vontade dos parlamentares, nem esses foram capazes de representar minimamente as expectativas da sociedade brasileira. A mesma situação perdurava em 1985, quando foi feita aprovar a Emenda Constitucional 26, que pretendeu conferir gabarito de norma constitucional à anistia.

Uma observação incidental a respeito da vigência da Emenda Constitucional 26/1985. Conquanto tenha previsto a convocação da Assembleia Constituinte que produziu a atual Constituição, a Emenda Constitucional 26 foi revogada com o advento da Constituição de 1988 e provavelmente mesmo antes, quando a Constituinte definiu seus rumos em sentido parcialmente divergente e autônomo (PAGLIARINI, 2009, p. 117-118). Isso porque a Carta Constitucional anterior, de 1969, previa como cláusulas pétreas a federação e a república, ${ }^{31}$ as quais deveriam subordinar a Emenda 
Constitucional 26, mas que foram ignoradas pela Assembleia Constituinte e solenemente contrariadas pela previsão de um plebiscito sobre forma e sistema de governo (art. $2^{\circ}$ do Ato das Disposições Constitucionais Transitórias da Constituição de 1988). ${ }^{32}$ Esse, portanto, poderia ter (re)instaurado a monarquia parlamentarista, embora seu resultado tenha mantido a república presidencialista. É possível, assim, sustentar que a Constituição de 1988 representou uma autêntica ruptura do ponto de vista jurídico, e seu processo de elaboração desvinculou-se do ato convocatório.

Se considerássemos a sucessão de normas, teríamos de concluir que a Lei n. 6.683/1979 fora revogada (absorvida) pela Emenda Constitucional 26/1985 que, por sua vez, foi também revogada pela Constituição atual. Entretanto, não foi esse o entendimento que prevaleceu por ocasião do julgamento da ADPF 153/DF, mas sim o de que a Lei n. 6.683 manteve-se sob a vigência da Emenda Constitucional 26/1985 e, posteriormente, foi recepcionada pela Constituição de 1988 .

A interpretação que presidiu a aplicação da Lei n. 6.683/1979 desde o início, no sentido de que a anistia atingiria tão bem os opositores do regime quanto os agentes públicos da repressão, foi uma leitura imposta. O Poder Judiciário e os outros sujeitos envolvidos na aplicação oficial do Direito não tinham condições de adotar interpretação diversa, inclusive porque parte significativa de seus integrantes estava comprometida com o regime.

A influência dos detentores do poder político-militar dessa época ainda é presente, conforme advertem Sabadell e Dimoulis (2011, p. 82), ao afirmar que os agentes da ditadura (militares e grupos conservadores) "até hoje não admitem questionamentos da atuação das forças de segurança durante o regime militar, nem desejam reavaliar o papel dos políticos e intelectuais brasileiros, amplamente comprometidos com as instituições daquele período”. Os autores dão como exemplo a previsão legislativa mais recente de pagamento de indenizações a vítimas do regime, que seria uma estratégia de blindagem, uma vez que não responsabiliza diretamente os agentes da ditadura "e, por isso, não modifica[m] a opção política 'anistiante"” (SABADELL; DIMOULIS, 2011, p. 82).

É convincente, portanto, o argumento de que não se aceita a autoanistia conferida pelos detentores do poder político-militar a atos de repressão política, e que os atos praticados por agentes públicos em nome do Estado não devem ser incluídos entre os abrangidos pela Lei n. 6.683/1979. Conquanto o Supremo Tribunal Federal, ao analisar a conformidade da Lei de Anistia com a Constituição brasileira, não se tenha deixado convencer pelo argumento, a Corte Interamericana adotou-o, na linha de precedentes, ao declarar a incompatibilidade da Lei n. 6.683 com a Convenção Americana de Direitos Humanos.

Assim, sob uma perspectiva internacionalista, a Lei de Anistia brasileira não se sustenta por um vício material e por um vício de origem. O vício material refere-se ao conteúdo dessa lei: graves violações a direitos fundamentais caracterizam-se como 
crimes contra a humanidade, que não são passíveis de anistia. Também materialmente, então, há uma ilegitimidade: os direitos humanos representam um mínimo ético que constitui o Direito, ou, como atestam Sampaio e Almeida (2009, p. 261), "o conteúdo ético passou a compor o direito como condição de legitimidade”.

$\mathrm{O}$ vício de origem refere-se à falta de legitimidade subjetiva: ainda que sejam tidos por políticos, tais atos (crimes) não podem ser anistiados por uma legislação espúria, cujos autores e intérpretes oficiais não tinham competência validamente outorgada para editá-la e aplicá-la. Lembra Weichert (2009, p. 147-148) que, quando editada a Lei n. 6.683/1979, "o país ainda estava sob o regime ditatorial. O Congresso Nacional estava mutilado pelas cassações e vivia sob a ameaça do recesso por ordem presidencial, conforme ocorrera apenas dois anos antes ('pacote' de abril de 1977 - Ato Complementar n. 102)"; além disso, houve eleição indireta para um terço do Senado os "senadores biônicos", que não passavam de "apadrinhados do governo".

\subsection{A dimensão transtemporal dos direitos FUndamentais:}

NÃO SE PODE RIFAR O DIREITO AO PASSADO (DIREITO À MEMÓRIA, À VERDADE E À REPARAÇÃO) Sendo certo que os direitos fundamentais apresentam-se sempre com atualidade em cada época presente e têm como porta-voz cada geração, eles, porém, também engajam futuro e passado e suscitam compromissos entre gerações: a Constituição e os tratados internacionais de direitos humanos são pactos intergeracionais.

Embora a dimensão "transtemporal" dos direitos fundamentais seja mais frequentemente relacionada ao futuro, como é o caso do direito fundamental a um ambiente ecologicamente equilibrado, ela compreende também uma perspectiva retrospectiva. As pessoas (e quem sabe outros seres) que tiveram existência histórica são titulares de direitos fundamentais, ainda que não os possam articular (reivindicar política e juridicamente, por exemplo) por razões óbvias; isso fica por conta de sujeitos atuais (indivíduos, associações, instituições oficiais etc.).

As gerações passadas são sujeitos de direitos fundamentais e continuam legítimos representantes da humanidade, tendo direito a que os conheçamos, conservemos suas experiências, compreendamos suas mensagens, atentemos para suas advertências ou simplesmente respeitemos sua existência histórica e permanência. Nós, do presente e do futuro, somos depositários responsáveis pela guarda daquilo que a todos pertenceu, pertence e pertencerá.

A "justiça de transição" suscita a dimensão transtemporal dos direitos fundamentais. Dimoulis (2009, p. 11-12), com base em Jon Elster, define a justiça de transição como "um processo de julgamentos, depurações e reparações que se realizam após a mudança de um regime político para um outro”. São apontadas três finalidades:

a) "satisfazer as vítimas" com reparações materiais ("indenizações, aposentadorias, reintegração ao serviço público, anulação de condenações”) e morais ("pedido de 
desculpas por autoridades estatais, abertura de arquivos, identificação dos agentes de repressão");

b) "pacificar a sociedade";

c) "evitar que se repita tal experiência", por meio de "reformas do Estado, campanhas de esclarecimento da opinião pública (...) e atos simbólicos de resgate da memória (monumentos, museus, exposições, instituição de datas comemorativas)”.

Compõem a justiça de transição direitos fundamentais do passado (memória), do presente (verdade) e do futuro (reparação), mas a memória é um legado (futuro), a verdade é um esclarecimento do passado e a reparação é um dever do presente; assim como a memória recebe sempre uma leitura presente do passado para o futuro, a verdade também é um testemunho para o futuro e a reparação é uma resposta para o passado, a mostrar o cruzamento intermodal desses aspectos.

Sob um enfoque político, pode-se, portanto, questionar a legitimidade de acordos que pretendem negociar direitos fundamentais gravemente violados no passado, mesmo quando algumas vítimas já não vivem mais. Sob um enfoque jurídico, pode-se questionar a validade de leis que pretendem neutralizar o caráter ilícito de graves violações a direitos fundamentais praticadas pela ditadura militar brasileira e que atingem inclusive os hoje mortos e de saparecidos.

Especificamente quanto ao direito à verdade, integra ele, reconhecidamente, "o catálogo dos direitos humanos no plano internacional”, tendo sido reconhecido pela UNESCO (o órgão da Organização das Nações Unidas para a Cultura) o "direito dos povos à integridade de sua memória escrita. As nações têm um direito, mas também um dever de preservar sua memória” - apontam Sampaio e Almeida (2009, p. 259).

\subsection{Competência da Corte Interamericana de Direitos Humanos}

É preciso verificar, ainda, a competência atual da Corte Interamericana de Direitos Humanos em relação a violações cometidas no passado. É certo que o Brasil aceitou a jurisdição internacional da Corte somente em 1998, ${ }^{33}$ como também é claro que essa aceitação deu-se com a ressalva expressa de que somente poderiam ser apreciados os "fatos ocorridos a partir do reconhecimento". ${ }^{34} \mathrm{O}$ óbice temporal à jurisdição da Corte Interamericana não significa, porém, uma impossibilidade absoluta de análise da questão. Se a Corte não tem competência para apreciar os acontecimentos anteriores àquele período, cabe a ela julgar o que se fez ou se deixou de fazer depois incluindo o presente - em relação aos crimes contra a humanidade então praticados e que são imprescritíveis.

Valiosos precedentes da mesma Corte indicam que "a ausência de investigação e persecução penal dessas condutas após essa data são, também, violações aos direitos 
humanos e aos compromissos assumidos pelo País na Convenção. E, sobre eles, a Corte tem competência para se pronunciar" (WEICHERT, 2009, p. 158-162). ${ }^{35} \mathrm{O}$ caráter permanente de alguns crimes então praticados (como a ocultação de corpos) e a omissão do Estado em investigar e punir tais atrocidades são condutas presentes, cuja atualidade autoriza a jurisdição da Corte Interamericana de Direitos Humanos.

\subsection{A decisão do Supremo Tribunal Federal}

Sabemos, contudo, que o Supremo Tribunal Federal, ao julgar a ADPF 153/DF, reconheceu a validade da Lei n 6.683/1979 em relação à Constituição de 1988 . Entendeu que:

a) as normas internacionais que serviriam de parâmetro interno para o contraste da Lei de Anistia (especialmente a Convenção das Nações Unidas contra a Tortura e Outros Tratamentos ou Penas Cruéis, Desumanos ou Degradantes) são posteriores (ou foram internalizadas posteriormente) e não vigoravam no Brasil à época. $\mathrm{O}$ Min. Cezar Peluso afirmou que, "[à]quela época, não havia, como hoje há, nenhum obstáculo de ordem constitucional nem legal para que o legislador estendesse a anistia aos crimes de qualquer natureza”;

b) a invocação de tais normas em face de uma lei de efeitos instantâneos ("lei-medida"), como é a Lei n. 6.683/1979, configura aplicação retroativa de lei mais gravosa, o que é vedado pela Constituição;

c) as violações perpetradas pelos agentes públicos durante a ditadura eram "crimes conexos" a que alude a Lei n. 6.683/1979, devendo a interpretação considerar "o momento histórico da sanção da lei";

d) a questão da prescrição somente teria relevância se fosse afirmada a existência de crimes, por força do afastamento da aplicação da Lei n. 6.683/1979, e que, ademais, a Convenção sobre a Imprescritibilidade dos Crimes de Guerra e dos Crimes contra a Humanidade (ONU, 1968) não tem vigência no Brasil, que a ela não aderiu. O Min. Gilmar Mendes lembrou que a jurisprudência brasileira considera que a superveniência da instituição da imprescritibilidade "não se aplica aos crimes já praticados";

e) não houve autoanistia, mas sim um amplo acordo político ("transição conciliada”), em que os vários atores sociais envolvidos participaram “de boa-fé". ${ }^{36} \mathrm{O}$ Min. Celso de Mello extrai da pretensa bilateralidade da Lei n. $6.683 / 1979$ (lei esta que não caracterizaria uma autoanistia) o diferencial a afastar os precedentes da Corte Interamericana de Direitos Humanos, que se refeririam a leis latino-americanas de anistia unilateral; 
f) a Lei n. 6.683/1979 foi devidamente aprovada pelo Congresso Nacional e que a "legitimidade política" deveria ser considerada então "em termos de paz social", em um "processo de participação da sociedade civil” (Min. Cármen Lúcia), sendo que a Lei n. 6.683 "nasceu de um acordo costurado por quem tinha legitimidade social e política para, naquele momento histórico, celebrar um pacto nacional” (Min. Cezar Peluso);

g) a Emenda Constitucional 26/1985 (logo, a anistia a que se refere) integra a ordem constitucional vigente, pois faz parte do processo constituinte originário, uma vez que foi por meio dessa Emenda que se convocou a Assembleia Constituinte. ${ }^{37} \mathrm{~A}$ propósito da suposta ilegitimidade do Congresso Nacional que aprovou a Emenda Constitucional 26, a Min. Cármen Lúcia rechaçou o argumento, sob a alegação de que senão "poderíamos chegar a questionar a própria Constituição de 1988”.

Em um ponto, porém, a decisão do Supremo Tribunal Federal acolhe uma expectativa em relação à "época negra” a que corresponde a última ditadura militar brasileira: afirma o direito fundamental de acesso a informações sobre o período. "Impõe-se [lê-se na parte final do acórdão] o desembaraço dos mecanismos que ainda dificultam o conhecimento do quanto ocorreu no Brasil durante as décadas sombrias da ditadura.” Esse aspecto, no entanto, não tem a ver diretamente com a Lei n. 6.683/1979, vez que o próprio Supremo Tribunal Federal assentou que a Lei de Anistia "não se qualifica como obstáculo jurídico à recuperação da memória histórica e ao conhecimento da verdade" (Min. Celso de Mello).

O estabelecimento da democracia será sempre uma empreitada provisória. O Direito tem a contribuir com a estabilização (garantia) do que se considere "conquista" e "aperfeiçoamento", mas sem impedir - ao contrário, com vistas a promover - novas perspectivas. A revisão de leis espúrias e a criação de leis adequadas apresentam momentos da experiência democrática. Nesse sentido, não há verdades absolutas e definitivas, ${ }^{38}$ senão uma incessante e séria busca, em primeiro lugar, por informações, e, em seguida, pela avaliação de sua correção (correspondência com a realidade), bem como um compromisso com a denúncia e reparação das injustiças cometidas. A recente promulgação da Lei n. 12.528/2011, que institui a Comissão Nacional da Verdade, participa desse processo alvissareiro.

\section{O Supremo Tribunal Federal reconhecendo a decisão da Corte INTERAMERICANA DE Direitos Humanos: AUTORIDADE INABALADA}

A decisão da Corte Interamericana de Direitos Humanos no caso Gomes Lund e outros vs. Brasil não infirma a avaliação do Supremo Tribunal Federal quanto à compatibilidade da Lei n. 6.683/1979 com a Constituição brasileira de 1988. Nem poderia ser afrontada a 
autoridade da Corte Suprema do Brasil, haja vista que lhe compete a análise da validade constitucional: o Supremo Tribunal Federal não realiza - nem pretendeu realizar na ADPF 153/DF - um exame objetivo (“abstrato”) da Lei n. 6.683/1979 à luz da Convenção Americana de Direitos Humanos; essa competência internacional cabe somente à Corte Interamericana.

A manifestação do Procurador-Geral da República na ADPF 153/DF - que foi acatada pelo Supremo Tribunal Federal -, no sentido de que "as cláusulas de compromisso, firmadas nesse processo [constituinte], [devem ser] respeitadas sob a nova ordem constitucional, sob pena de negar-se ao Direito a força que possui de integração social e de estabilizador das expectativas gerais de comportamento. / Especialmente quando essas cláusulas se tornam normas jurídicas, como sucedeu com a Lei de Anistia”, igualmente não se contrapõe àquela decisão internacional. O pronunciamento do Chefe do Ministério Público da União traduz uma avaliação positiva acerca da recepção da Lei n. 6.683/1979 pela Constituição de 1988 (ou seja, um juízo de constitucionalidade) que de forma alguma é desmerecido pela conclusão da Corte Interamericana de Direitos Humanos. O Procurador-Geral da República também não teceu considerações acerca da convencionalidade da Lei de Anistia, nem adentrou, portanto, o âmbito de jurisdição (internacional) da Corte Interamericana.

Porém, como as conclusões judiciais situam-se em âmbitos diversos e não colidentes (o plano interno do Supremo Tribunal Federal e o plano internacional da Corte Interamericana), é preciso compatibilizar os pronunciamentos divergentes. Essa compatibilização será feita com o acatamento da decisão mais recente da Corte Interamericana de Direitos Humanos: a invalidade da Lei n. 6.683/1979.

Tendo o Conselho Federal da Ordem dos Advogados do Brasil oposto embargos de declaração ao acórdão da ADPF 153/DF, abriu-se uma excelente oportunidade para que o Supremo Tribunal Federal pudesse esclarecer o alcance de sua decisão. Uma “obscuridade superveniente" advinda do pronunciamento posterior da Corte Interamericana poderá ser altivamente superada por manifestação do Supremo Tribunal alinhando-se à jurisdição interamericana.

Por esse viés, será reforçada a autoridade do Supremo Tribunal Federal enquanto guardião maior da Constituição brasileira, pois se oportunizará ao próprio Supremo Tribunal Federal que explicite o âmbito nacional de sua jurisdição (atinente à constitucionalidade da Lei n. 6.683/1979) e o âmbito internacional da jurisdição da Corte Interamericana de Direitos Humanos (atinente à inconvencionalidade da Lei n. 6.683/1979). Conhecer dos embargos para dar-lhes provimento e determinar a observância do quanto decidido em termos de compatibilidade com a Convenção Americana de Direitos Humanos pela Corte Interamericana será, portanto, uma afirmação soberana de autoridade por parte do Supremo Tribunal Federal.

Ao acolher os embargos de declaração, o Supremo Tribunal Federal estará, a um tempo, integrando sua própria decisão relativa à ADPF 153/DF e executando a decisão 
da Corte Interamericana de Direitos Humanos no caso Gomes Lund e outros vs. Brasil. O oportuno esclarecimento do Supremo Tribunal Federal representará o exato cumprimento de determinação constante da decisão da Corte Interamericana, no sentido de que "o Estado deve conduzir eficazmente a investigação penal dos fatos do presente caso, a fim de esclarecê-los, determinar as correspondentes responsabilidades penais e aplicar efetivamente as sanções e consequências que a lei disponha”. ${ }^{39}$ Nessa medida, o importante reconhecimento da decisão da Corte Interamericana pelo próprio Supremo Tribunal Federal será já uma etapa do cumprimento dessa decisão. Direito Constitucional e Direito Internacional saberão ser magistralmente compatibilizados pela Corte Suprema do Brasil.

: ARTIGO APROVADO (02/12/2013) : RECEBIDO EM 27/08/2012

\section{NOTAS}

1 Veja-se uma crítica da decisão do Supremo Tribunal Federal na ADPF 153/DF em (WEICHERT, 2009(2)), crítica à qual adiro.

2 São contra Sabadell e Dimoulis (2011, p. 86). Os autores sustentam que "a decisão da Corte interamericana não tem o condão de afastar uma decisão do STF em sede de ADPF” e que a Lei n. 9.882/1999, que regulamenta a ADPF, contém a determinação de que tal decisão "terá eficácia contra todos e efeito vinculante relativamente aos demais órgãos do Poder Público" (art. 10, § $3^{\circ}$ ).

3 Sarmento (texto inédito, 2011) anota: "Não houve manifestação do Plenário do STF sobre afronta ao Pacto de San Jose da Costa Rica, porque este, de acordo com a orientação jurisprudencial da Corte, não integra o nosso bloco de constitucionalidade, revestindo-se de hierarquia supralegal, mas infraconstitucional... Portanto, não era da competência da Corte Suprema apreciar esta questão, tendo em vista que, ao julgar uma ADPF, o STF exerce o controle de constitucionalidade dos atos normativos, mas não fiscaliza a sua convencionalidade.”

4 Para a autora (p. 106), a definição de "empréstimo jurídico" é restrita ao Direito estrangeiro, ou seja, não comporta o Direito Internacional: a "assimilação voluntária de determinadas normas provenientes do direito de outras nações”.

5 Lei n. 8.009/1990, art. $3^{\circ}$, VII.

6 "Toda pessoa tem direito a um padrão de vida capaz de assegurar a si e a sua família saúde e bem-estar, inclusive alimentação, vestuário, habitação, cuidados médicos e os serviços sociais indispensáveis, o direito à segurança, em caso de desemprego, doença, invalidez, viuvez, velhice ou outros casos de perda dos meios de subsistência em circunstâncias fora de seu controle."

7 Decidiu-se pela inconstitucionalidade da Lei de Crimes Hediondos (Lei n. 8.072/1990), art. $2^{\circ}$, § $1^{\circ}$.

8 "As penas privativas de liberdade devem ter por finalidade essencial a reforma e a readaptação social dos condenados." 
9 "Ninguém pode ser submetido à detenção ou encarceramento arbitrários."

10 Decidiu-se pela constitucionalidade do art. $5^{\circ}$ da Lei n. 11.105/2005 (Lei da Biossegurança).

11 "Toda pessoa tem o direto de que se respeite sua vida. Esse direito deve ser protegido pela lei e, em geral, desde o momento da concepção. Ninguém pode ser privado da vida arbitrariamente.” Note-se que o Min. Menezes Direito foi voto vencido pela inconstitucionalidade.

12 “Art. 10. Nenhuma pesquisa do genoma humano ou das suas aplicações, em especial nos campos da biologia, genética e medicina, deverá prevalecer sobre o respeito aos direitos humanos, às liberdades fundamentais e à dignidade humana de pessoas ou, quando aplicável, de grupos de pessoas”; “Art. 11. Não é permitida qualquer prática contrária à dignidade humana, como a clonagem reprodutiva de seres humanos. Os Estados e as organizações internacionais pertinentes são convidados a cooperar na identificação dessas práticas e na implementação, em níveis nacional ou internacional, das medidas necessárias para assegurar o respeito aos princípios estabelecidos na presente Declaração.” Note-se que a Min. Cármen Lúcia votou pela constitucionalidade.

13 “[A presente Declaração tem os seguintes objetivos:] reconhecer a importância da liberdade de investigação científica e dos benefícios decorrentes dos progressos da ciência e da tecnologia, salientando ao mesmo tempo a necessidade de que essa investigação e os consequentes progressos se insiram no quadro dos princípios éticos enunciados na presente Declaração e respeitem a dignidade humana, os direitos humanos e as liberdades fundamentais." Note-se que o Min. Ricardo Lewandowski votou pela constitucionalidade, porém sob diversos condicionamentos.

14 “Ninguém poderá ser preso apenas por não poder cumprir com uma obrigação contratual."

15 "Ninguém deve ser detido por dívidas. Este princípio não limita os mandados de autoridade judiciária competente expedidos em virtude de inadimplemento de obrigação alimentar.”

16 Decidiu-se pela não recepção da Lei n. 5.250/1967.

17 Sobre a "Liberdade de pensamento e de expressão".

18 Resultantes de conferência da Comissão Internacional de Juristas e do Serviço Internacional de Direitos Humanos. O Princípio 24 dispõe: "Toda pessoa tem o direito de constituir uma família, independente de sua orientação sexual ou identidade de gênero. As famílias existem em diversas formas. Nenhuma família pode ser sujeita à discriminação com base na orientação sexual ou identidade de gênero de qualquer de seus membros.”

19 O autor alude à bricolagem ("bricolage”), em que o intérprete tem predisposição para utilizar outras fontes normativas, mas "recorre a experiências estrangeiras de maneira mais ou menos aleatória" (Luiz Magno Pinto Bastos Júnior).

20 Acórdão Vermeira v. Bélgica (1991), sobre a "revisão do Código Civil belga para estender o direito de suceder aos filhos nascidos fora do vínculo matrimonial” (FIGUEIREDO, 2009, p. 66-67).

21 Veja-se tal preocupação com um enfoque especificamente jurídico - embora com conclusões diversas - em (SWENSSON JR., 2010, p. 27-28 e 35).

22 Art. $5^{\circ}$, XXXIX ("não há crime sem lei anterior que o defina, nem pena sem prévia cominação legal”) e XL ("a lei penal não retroagirá, salvo para beneficiar o réu”).

23 Art. XI.2 ("Ninguém poderá ser culpado por qualquer ação ou omissão que, no momento, não constituam delito perante o direito nacional ou internacional. Também não será imposta pena mais forte do que aquela que, no momento da prática, era aplicável ao ato delituoso.”).

24 Art. $9^{\circ}$ - Princípio da legalidade e da retroatividade ("Ninguém poderá ser condenado por atos ou omissões que, no momento em que foram cometidos, não constituam delito, de acordo com o direito aplicável. Tampouco poderse-á impor pena mais grave do que a aplicável no momento da ocorrência do delito. Se, depois de perpetrado o delito, a lei estipular a imposição de pena mais leve, o delinquente deverá dela beneficiar-se."). 
25 Sabadell e Dimoulis (2011, p. 87) asseveram, em sentido oposto, que "o direito brasileiro vigente em 1979 não incluía normas de origem nacional ou internacional que tipificassem crimes contra a humanidade e determinassem sua imprescritibilidade; tampouco era prevista vedação de anistia ou pelo menos de autoanistia”.

26 Art. $6^{\circ}$.c.

27 Pela insuficiência do costume internacional para o Direito Criminal, veja-se (SWENSSON JR., 2010, p. 42).

28 São citados precedentes do STF: RE 56.466/DF, rel. Min. Bilac Pinto, 1973; ACO 298/DF, rel. p/ acórdão Min. Décio Miranda; AC 9.696/SP, rel. Min. Sydney Sanches, 1989 (este o caso referido no texto).

29 Contra, Ana Lucia Sabadell e Dimitri Dimoulis (2011, p. 93): "Decidir responsabilizar os agentes da ditadura décadas após a ocorrência dos fatos gera uma responsabilização não esperada que muda retroativamente a valoração de certos fatos."

30 Tavares e Agra (2009, p. 70) acentuam a dimensão moral como “um imperativo ético incontornável”.

31 Art. 47, § 1: “Não será objeto de deliberação a proposta de emenda tendente a abolir a Federação ou a República.”

32 ADCT, art. $2^{\circ}$, caput: "No dia 7 de setembro de 1993 o eleitorado definirá, através de plebiscito, a forma (república ou monarquia constitucional) e o sistema de governo (parlamentarismo ou presidencialismo) que devem vigorar no País."

33 Decreto-Legislativo 89, de 3 de dezembro de 1998.

34 A ressalva é autorizada pelo art. 62 da Convenção Americana de Direitos Humanos.

35 São referidos os casos Comunidad Moiwana v. Suriname e Almonacid Arellano v. Chile.

36 O Min. Cezar Peluso chega a afirmar que a autoanistia é reconhecidamente "censurada pelos tribunais internacionais", mas reforça que disso não se trata, pois a Lei n. 6.683 teria sido oriunda de um acordo.

37 Neste ponto, a Min. Cármen Lúcia diverge, por entender que a Emenda Constitucional 26 foi revogada pela Constituição de 1988 .

38 Contundente crítica da concepção essencialista da verdade encontra-se em Sabadell e Dimoulis (2011, p. 89): "Eventual direito à verdade a ser satisfeito mediante prestação estatal contraria o princípio democrático que tem como componente central o pluralismo e a tolerância. Dito de maneira simples, o objetivo da verdade oficial garantida pelo Estado corresponde muito mais a ditaduras do que a democracias."

39 Ponto 256 da "sentença".

\section{REFERÊNCIAS BIBLIOGRÁFICAS}

ARAGON REYES, Manuel. La constitución como paradigma. In: CARBONELL, Miguel (Coord.). Teoría del neoconstitucionalismo. Ensayos escogidos. Madrid: Trotta, 2007, p. 38-39.

CANOTILHO, J. J. Gomes. "Brancosos” e interconstitucionalidade. Itinerários dos discursos sobre a historicidade constitucional. Coimbra: Almedina, 2006.

; MOREIRA, Vital. Constituição da República Portuguesa anotada-Volume I. 4.ed. Coimbra: Coimbra; 1.

ed. São Paulo: Revista dos Tribunais, 2007. 
CARVALHO RAMOS, André de. O primeiro ano da sentença da Guerrilha do Araguaia. In: Consultor Jurídico. Disponível em: <http://www.conjur.com.br/2011-nov-24/ano-depois-sentenca-guerrilha-araguaia-nao-foicumprida $>$. Acesso em 12 de janeiro de 2012.

A expansão do Direito Internacional e a Constituição brasileira: novos desafios. In: SAMPAIO, José Adércio Leite (org.). Crise e desafios da constituição. Belo Horizonte: Del Rey, 2004, p. 291-320.

DIMOULIS, Dimitri. O caso dos denunciantes invejosos. Introdução prática às relações entre direito, moral e justiça. 5.ed. São Paulo: Revista dos Tribunais, 2009.

FAVOREU, Louis et al. Droit constitutionnel. 4.ed. Paris: Dalloz, 2001.

FIGUEIREDO, Marcelo. Notas a respeito da utilização de jurisprudência estrangeira pelo Supremo Tribunal Federal no Brasil. Revista Brasileira de Estudos Constitucionais - RBEC, Belo Horizonte, ano 3, n. 12, p. 57-69, out./dez. 2009.

GUTMANN, Amy; THOMPSON, Dennis. Why deliberative democracy? Princeton: Princeton University Press, 2004. ; THOMPSON, Dennis. O que significa democracia deliberativa. Revista Brasileira de Estudos

Constitucionais - RBEC, Belo Horizonte, ano 1, n. 1, p. 17-78, jan./mar. 2007.

KUNDERA, Milan. O livro do riso e do esquecimento. Rio de Janeiro: Nova Fronteira, 1987.

NEVES, Marcelo. Transconstitucionalismo. São Paulo: WMF Martins Fontes, 2009.

NINO, Carlos. Juicio al mal absoluto. Buenos Aires: Ariel, 2006.

OST, François. O tempo do direito. Bauru: Edusc, 2005.

PAGLIARINI, Alexandre Coutinho. Tratado de Lisboa: a significação de um novo Direito Constitucional? Revista Brasileira de Estudos Constitucionais - RBEC, Belo Horizonte, ano 3, n. 11, p. 115-135, jul./set. 2009.

ROTHENBURG, Walter Claudius. Direito constitucional. São Paulo: Verbatim, 2010.

SABADELl, Ana Lucia. Manual de sociologia jurídica. 3.ed. São Paulo: Revista dos Tribunais, 2005. ; DIMOULIS, Dimitri. Anistia. A política além da justiça e da verdade. Acervo, v. 24, 2011, p. 79-102.

SAMPAIO, José Adércio Leite; ALMEIDA, Alex Luciano Valadares de. Verdade e história: por um direito fundamental à verdade. In: SOARES, Inês Virgínia Prado; KISHI, Sandra Akemi Shimada (Coord.). Memória e verdade: a justiça de transição no Estado Democrático brasileiro. Belo Horizonte: Fórum, 2009, p. 249-272.

SARLET, Ingo Wolfgang. A assim designada proibição de retrocesso social e a construção de um direito constitucional comum latino-americano. Revista Brasileira de Estudos Constitucionais - RBEC, Belo Horizonte, ano 3, n. 11, p. 167-204, jul./set. 2009.

SARMENTO, Daniel. Manifestação sobre a inexistência de contradição entre a decisão do STF na ADPF n. 153 e a sentença da Corte Interamericana de Direitos Humanos no caso Gomes Lund e outros vs. Brasil (texto inédito), 2011.

SWENSSON Junior, Lauro Joppert. Punição para os crimes da ditadura militar: contornos do debate. In:

DIMOULIS, Dimitri; MARTINS, Antonio; SWENSSON Junior, Lauro Joppert (Org.). Justiça de transição no Brasil. Direito, responsabilidade e verdade. São Paulo: Saraiva, 2010, p. 23-59.

TAVARES, André Ramos. Modelos de uso da jurisprudência constitucional estrangeira pela justiça constitucional. Revista Brasileira de Estudos Constitucionais - RBEC, Belo Horizonte, ano 3, n. 12, p. 17-55, out./dez. 2009.

TAVARES, André Ramos; AGRA, Walber de Moura. Justiça reparadora no Brasil. In: SOARES, Inês Virgínia Prado; KISHI, Sandra Akemi Shimada (Coord.). Memória e verdade: a justiça de transição no Estado Democrático brasileiro. Belo Horizonte: Fórum, 2009, p. 69-91.

WEICHERT, Marlon Alberto; FÁVERO Eugênia Augusta Gonzaga. A responsabilidade por crimes contra a humanidade cometidos durante a ditadura militar. In: SOUZA Neto, Cláudio Pereira de; SARMENTO, Daniel; BINENBOJM, Gustavo (Coord.). Vinte anos da Constituição Federal de 1988. Rio de Janeiro: Lumen Juris, 2009, p. 511-568.

WEICHERT, Marlon Alberto. Anistia a graves violações a direitos humanos no Brasil: um caso de suprema impunidade. Revista OABRJ, Rio de Janeiro, v. 25, n. 2, p. 137-164, jul./dez. 2009.

\section{Walter Claudius Rothenburg}

Rua Euclides da Cunha, n. 233

Nova América - 13417-660

Piracicaba - SP - Brasil

walter claudiuslaterra com br
Procurador Regional da República NO MinistéRIO PúBlico FEDERAL

Professor de Mestrado e Doutorado na Instituição Toledo de Ensino (ITE) 
